\title{
A CONFIGURAÇÃO DO GÊNERO CÔMICO
}

De Carli, Elisana ${ }^{1}$

O teatro se configura pelo imbricamento da linguagem verbal elou não-verbal, do texto e do paratexto (rubrica), do diálogo e da cena; em termos gregos, a lexis : a elocução, o discurso, texto dramático, e a opsis: o que se vê, o espetáculo. Tal configuração se torna mais latente no gênero cômico, no qual a visualidade e a ação no palco, em grande parte, apresentam elementos que proporcionam a efetividade da comédia bem como potencializam a proposição do riso presente no texto dramático. Partindo da Grécia antiga e pontuando diferentes momentos estéticos e históricos, este estudo busca apresentar a configuração deste gênero e seus elementos centrais, destacando quais permanecem quer no teatro clássico, quer em outras manifestações contemporâneas, como programas televisivos e o stand up comedy. Tomando em linhas gerais, com uma visão prelimiar, o gênero cômico tem seus fluxos e influxos, com alterações, mas permanecendo presente no cânone ocidental, diferentemente da tragédia que sofre um declínio. Essa força é resultado de uma característica essencial da comédia que é o foco sobre o cotidiano; perspectiva esta que pode também significar seu engessamento, pois este olhar pode se tornar pontual e sem reverberação, sobremaneira datado pelas referências especificas, difíceis de serem retomadas posteriormente. Contudo é justamente esse olhar sobre sua contemporaneidade que permite seu fluxo e alterações, permitindo ir além, contrapondo-se novamente a estrutura mais rígida do gênero trágico, a qual possivelmente foi amalgamada pela força dos teóricos.

O gênero cômico, na atualidade, apresenta variados referenciais e é encontrado em diferentes meios de difusão. No teatro temos a comédia, tragicomédia; no cinema, há comédia romântica; na televisão, programas humorísticos; o stand up. Deste breve elenco, que não esgota as proposições estéticas, há elementos que atravessam os séculos na configuração da comédia. Um desses elementos é o personagem tipo, considerado plano, sem complexidades e alterações ao longo da trama, tendo uma característica destacada, que de modo

\footnotetext{
${ }^{1}$ Universidade Federal de Santa Catarina (UFSC). elisana.carli@ufsc.br
} 
geral, o define: o apaixonado, o ingênuo, o velho ranzinza, a mulher frívola, o esperto, o avarento, entre outros. Quanto ao enredo, o chamado 'final feliz', quando tudo termina bem, ocorrendo uma reconciliação, é outro fundamento. Também a menção à personalidades da época abordada, figuras de destaque em uma sociedade, é matéria comum e produtiva no gênero cômico, marcando sua ligação com os acontecimentos locais e do cotidiano. Em termos de estrutura, o artificio do engano, do logro, sendo consciente ou não, é artificio fundamental para gerar a progressão dramática através de confusões, consequentemente proporcionando risos. Ainda, a presença da violência, esta podendo ser verbal, simbólica, física, é matéria peculiar e consistente na configuração do gênero cômico ao longo dos séculos.

Tendo esses elementos como parâmetros apontamos, a partir de uma perspectiva diacrônica, a sua composição e efetividade na comédia. Partindo da Grécia antiga, o personagem tipo é figura constante na proposição cômica como se constata em autores como Cratino (c.515- 423 a.C.), Êupolis (c. 446 - 411 a .C.), Hermipo (ativo entre 435 a 415 a.C.), Crates (c. 449 a.C.), anteriores e contemporâneos a Aristófanes (c.448-380 a.C.), que apresentam o careca; a velha bêbada; o velho com a bengala, que representa um índice e símbolo de pancadaria e de obscenidade (outra constante na comédia), bem como o personagem do escravo. Seu papel é fundamental, pois além de poder transitar pelos diferentes espaços, levando informação da casa do senhorio à praça e vice-versa, interagindo com diferentes personagens, recurso importante na conformação e progressão da trama, é ele, esperto, habilidoso, perspicaz, que, de modo geral, salva a seu parvo senhor. Esse par é tão produtivo que se reconfigura ao longo do tempo sendo apresentados como patrão e empregado; cavaleiro e ajudante; os criados (zanni) da Commedia dell'arte, compondo-se um criado esperto e o outro, o ingênuo. A mudança de referência, ainda que de alguma maneira a relação de poder se mantenha, é exemplo da dinâmica da comédia, atenta ao cotidiano da realidade social, política e econômica dos períodos em que é produzida. Essa acepção e a conformação do personagem tipo demarcam também este movimento estético de grande repercussão que é a comédia dell’arte, que é uma das marcas do gênero. Assim temos, o personagem do Capitão, que é medroso, falastrão, possivelmente inspirado no Miles Gloriosus, (O soldado fanfarrão), comédia de Plauto; o Pantaleão, um homem velho, rico, que tem uma filha; o Doutor, com sua toga preta com gola 
branca, a fazer citações em latim, com uma falsa erudição. Vale destacar que, também chamada de comédia do improviso, justamente por estar pautada no jogo teatral, exigindo habilidades técnicas dos atores, potencializa a força do espetáculo. Contrapondo-se à comédia erudita, literária, assim excetuando-se do texto teatral tradicional, originada e consolidada na Itália, repercute por toda Europa, com forte influência na França, se torna um marco na história do teatro, enfatizando o trabalho do ator, em certa medida, reflexo das manifestações artísticas do período medieval expressas pelos artistas de mimo, forma teatral de sucesso na Antiguidade. (Portich, 2008; Berthold, 2003).

Frye (1957, p.49) considera que habitualmente o gênero cômico propõe a incorporação de uma personagem, compondo assim uma forma de integração da sociedade, haja vista o tom discrepante que são revelados pelos personagens, de modo geral, com excessos que se distanciam de um equilíbrio e revelam a heterogeneidade do humano. Essa perspectiva nos faz aludir a Diomedes, gramático do século IV, que considera a comédia um gênero de consolidação da vida (ao passo que a tragédia seria de dissolução) (Diomedes apud Carlson, 1997). $\mathrm{Na}$ Poética, Aristóteles afirma que a "comédia é imitação de homens inferiores; não todavia, quanto a toda espécie de vícios, mas só quanto àquela parte do torpe que considera ridículo." (1449 a 32). Entre tantas analises sobre a poética aristotélica, destacamos neste estudo a consideração de Bender (1996, p.23) que observa que "essa inferioridade deve ser entendida como o resultado do herói apresentar falhas ou vícios risíveis por sua insignificância", sem representar danos severos a ele e/ou aos demais personagens. O que se depreende, então, assinalado também pela pela dramaturgia, é uma variedade de personagens e na sua definição, como pontua Evâncio (século IV), em De fabula, que "na comédia, os homens são de classe média, leves os perigos, felizes os desfechos" (apud Carlson, 1997, p.25). Assim, os exemplos configuram a mistura dos níveis existentes - animal, humano, divino visto que nada está estanque ou excluído, sendo os personagens de toda ordem, com objetivos variados, apresentados através de uma linguagem coloquial, muitas vezes, sob os auspícios de Dioniso (embriaguez) e de Afrodite (sexualidade): eis o kommos. (GIRARD, 1980, p.14)

Nesta organização da comédia, Aristófanes é um interlocutor da tradição já existente na Grécia com a sua contemporaneidade, com a busca por novos caminhos. Assim, mantém o coro com animais, mas "recomenda excluir o córdax 
(dança cómica), a qual trata-se de um ritmo lascivo, associado à embriaguez, de que a personagem da velha enrugada e sem dentes parece ter sido executante privilegiada" (SILVA, 1991, p.210). De acordo com Murray, "Aristófanes soube recuperar esses padrões, de modo a 'purificar e intelectualizar gradualmente uma estranha representação, sem contudo deixar esvair-se-lhe o cómico burlesco ou reduzir-se a sua intensa vitalidade”.(Murray apud SILVA, 1991, p. 213). A produção na Antiguidade grega é grande e significativa, contudo chegou até nós apenas textos inteiros de Aristófanes, cujas obras indicam um trabalho estético consistente, com variações. Um dos argumentos que notificam a força do gênero cômico neste período, além das listas de títulos e autores, é a classificação que ainda utilizamos como comédia antiga, médialintermediária e nova, a qual é uma classificação tardia.

Vale destacar que no século $X X$ foi encontrado um manuscrito de uma comédia de outro comediógrafo grego, Menandro (c.342 - 291 a.C.), autor caracterizado junto aos padrões da comédia nova, a qual é vinculada às comédias de Plauto (c.255-185 a.C.) e Terêncio (c.185 - 159 a.C.), na Roma antiga, reiterando a comédia, sem a presença do coro, pautada nos temas da vida privada, como o amor entre os jovens, o embate entre jovens e velhos, vividos por personagens tipo, o uso da violência, tudo permeado pelo recurso do logro. Mas, há uma distensão na composição entre estes dois autores que repercute na conformação da comédia e do teatro de modo geral. Estes dramaturgos apresentam uma composição diversa, tendo as comédias plautinas um riso fácil, criado pelo uso do logro, dos enganos e confusões ao par que as terencianas buscam uma proposição moral, a partir de personagens que fogem, em parte, do estereótipo ( como uma sogra boa; uma prostituta solidária). As comédias de Terêncio são consideradas por Diderot como protótipo do drama sério; segundo Paratore, seria o primeiro e grande drama burguês da literatura mundial.

Ao analisar a composição do gênero cômico, e isso vale para Plauto e Terêncio, é importante lembrar que "cômico não recobre totalmente a comédia enquanto gênero, e só uma interpretação desatenta fará coincidir, de uma vez por todas, comédia com riso." (Areas, 1990, p.10). Assim, esta pesquisa busca a análise da comédia enquanto gênero e não especificamente com os meandros de construção do cômico como humor e riso. Desse modo, a perspectiva de uma trama que termina em reconciliação, um 'final feliz', ou personagens inferiores, ou comuns, do povo, ou apresentando perigos leves, podem ser parâmetros de configuração da 
comédia. Neste contexto nos deparamos com peças como $A$ sogra, de Terêncio , $A$ mandrágora, de Maquiavel, Arlequim servidor de dois amos, de Goldoni, $O$ avarento, de Moliére, Fuenteovejuna, de Lope de Vega, A vida é sonho, de Calderón de la Barca, O mercador de Veneza, de Shakespeare: uma rápida seleção do que compõe a heterogeneidade do gênero cômico.

Atualmente, a ideia de comédia é rapidamente relacionada ao riso. Além da configuração do próprio espetáculo, como exemplo, pode-se indicar também a forma pela qual as propagandas de comédias é apresentada para atrair o público: "morra de rir"; "uma noite inteira de risadas"; "ria a noite toda ou o seu dinheiro de volta"; "para cair da cadeira de tanto rir". Acredito que nesse quesito, somos descendentes da comédia de Plauto: queremos um riso fácil. Nesse contexto tem-se os programas televisivos, como Zorra Total, Vai que cola, Os trapalhões, ou os espetáculos de stand up.

Ainda que sejam expressões contemporâneas do gênero cômico é possível encontrar estruturas tradicionais como os personagens tipo, o uso da violência física, verbal, e simbólica; a menção à personalidades reconhecidas da sociedade. O personagem fixo e tipificado é o mote de programas televisivos, que reiteram clichês, como a moça que procura um homem rico para casar; o rapaz apaixonado que não se declara; o gay escandaloso; que retratam um tema do cotidiano da sociedade, em uma trama com final feliz. Também destaca-se a quebra da ilusão dramática, característica da comédia, a qual pode ocorrer de formas variadas e com diferentes objetivos. Deste rápido elenco de características dessas apresentações contemporâneas podemos retomar os elementos constantes na comedia: o personagem tipo; vícios e rebaixamentos; referências ao cotidiano (tema, linguagem, personagens); a menção à personalidades da época abordada (figuras de destaque em uma sociedade), podendo ser um destaque, um ataque, uma parodialsátira; (explicito ou implícito); o engano (consciente ou não); a violência (verbal, simbólica, física); o final feliz (tudo termina bem).

Entre as manifestações contemporâneas, o stand up comedy ganhou, nos últimos anos, os palcos e os espectadores no Brasil. De acordo com Mintz (1985), seria a forma mais antiga, básica, universal de expressão de humor. Nas palavras do professor Fabio Salvatti, pesquisador das vertentes atuais do gênero cômico, "O Stand Up Comedy é uma apresentação pública de gênero cômico, predominantemente solo, sem cenário, figurinos e adereços, com texto criado pelo 
próprio comediante, frequentemente sobre suas experiências pessoais ou sobre suas observações sobre o cotidiano." De modo geral, o texto apresentado pauta-se em temas do cotidiano, com foco em grupos minoritários, relacionados à aparência física, gênero, sexualidade, destacando-se pelo modo violento de tratar os envolvidos, os quais podem ser indicados por seus nomes, especialmente quando figuras públicas reconhecidas. Ainda, no discurso stand up, a referência ao gay, à loira, o/a gordo/a pode fazer referência a todo um grupo, reiterando clichês e, muitas vezes, preconceitos. Este ataque público e nominal é uma das matrizes do gênero cômico na antiga Grécia, antes mesmo de Aristófanes, o qual também se utilizou deste expediente, configurando-se assim, como um dos fios condutores da comédia. Percebe-se, assim, em manifestações atuais do humor, a manutenção de recursos tradicionais do gênero cômico.

Contudo, apesar da identificação de elementos recorrentes que possibilitam demarcar um configuração geral da comédia em diferentes períodos históricos e estéticos, como ressalta Vilma Areas: "Apesar de extensa literatura sobre o assunto, até hoje não se tem uma base satisfatória para o estudo do gênero cômico, seus limites e o proposito estético que o anima." (1990, p.9). Entendo que esta é justamente a engrenagem que faz com o que gênero mantenha sua dinâmica $e$ fluidez, essencial para a análise do cotidiano, uma das características da comédia. A proximidade com as questões imediatas das sociedades, somadas a outros fatores como a inexistência de uma sistematização teórica, como a feita por Aristóteles com a tragédia, e na qual aponta este mesmo autor sobre a conformação do gênero cômico: "Se as transformações da tragédia e seus autores nos são conhecidas, as da comédia, pelo contrário, estão ocultas, pois que delas se não cuidou desde o início: só muito tempo o arconte concedeu o coro da comédia, que outrora era constituído por voluntários. (1449 a 36). Tal encaminhamento pode, de algum modo, ter favorecido a perspectiva de independência do gênero quanto a sistematizações e teorias conformadoras, o que possibilitou a sua produtividade e permanência ao longo dos séculos.

\section{REFERÊNCIAS}


AREAS, Vilma. Iniciação à comédia. Rio de Janeiro: Jorge Zahar editor, 1990.

ARISTÓTELES. Poética. Trad. E notas de Eudoro de Souza. São Paulo: Nova Cultural, 1987.

BENDER, I. Comédia e riso: uma poética do teatro cômico. Porto Alegre, editora Universidade/ UFRGS/EDPUCRS, 1996.

BERTHOLD, M. História Mundial do Teatro. 3.ed. São Paulo: Editora Perspectiva, 2006.

CARLSON, M. Teorias do teatro: estudo histórico-critico dos gregos à atualidade. Trad. Gilson de Souza. São Paulo: Ed. Unesp, 1997.

HUNTER, R. L. A comédia nova da Grécia e de Roma. Trad. Reodrigo Gonçalves et al. Curitiba: Ed.UFPR, 2010.

MINTZ, Lawrence. Standup comedy as social and cultural mediation. American Quarterly, Vol. 37, No. 1, Special Issue: American Humor (Spring, 1985), pp. 71 -80.

GIRARD, Gilles; OUELLET, Réal; RIGAULT, Claude. O universo do teatro. Trad. Maria H. Arinto. Coimbra:Almedina, 1980.

PORTICH, Ana. A arte do ator entre os séculos XVI e XVIII - da Commedia Dell 'Arte ao paradoxo sobre o comediante. São Paulo:Perspectiva:Fapesp, 2008 ROUBINE, J-J. Introdução às grandes teorias do teatro. Trad. Andre Telles. Rio de Janeiro: Jorge Zahar Ed., 2003.

SOUSA E SILVA, M. F: Crítica do teatro na comédia antiga. Coimbra: INIC, 1987. 